\title{
Resenha de Arte e técnica em Heidegger, de Irene Borges-Duarte (Lisboa: Documenta, 2014)
}

\author{
Chiara Pasqualin \\ chiarapasqualin@hotmail.it \\ (Universidade de São Paulo, São Paulo, Brasil
}

DOI: http://dx.doi.org/10.11606/issn.2318-9800.v21i1p131-138

O livro de Borges-Duarte propõe uma investigação límpida e rica sobre as questões entrelaçadas de arte e técnica, consideradas como fios condutores da reflexão heideggeriana posterior à Ontologia Fundamental. A contribuição original da autora não se endereça apenas aos especialistas de Heidegger, mas se apresenta também como uma imprescindível introdução ao pensamento do filósofo, pelo menos no que diz respeito ao período que vai desde inícios dos anos 1930 até o final dos anos 1960. Excluindo o primeiro capítulo, que oferece uma visão geral e introdutiva dos conteúdos apresentados, o volume reúne sete ensaios, concebidos originariamente como trabalhos autônomos, mas coesos em seus objetivos. Enfeitam o volume tanto a tradução inédita de alguns textos menos conhecidos de Heidegger, quanto a inserção de reproduções das obras de arte mais significativas a que Heidegger se refere nos seus escritos. Entramos, dessa maneira, não somente no processo genético da elaboração de algumas ideias centrais do filósofo, mas, especialmente, no seu "imaginário" íntimo, que é assim desvelado ao leitor.

O segundo capítulo se dedica à análise da entrevista concedida por Heidegger à revista alemã Der Spiegel em 1966, publicada postumamente. A autora lê esse breve texto não tanto como documento biográfico, mas como uma via de acesso preferencial aos densos assuntos do pensamento heideggeriano. Baseando-se no comentário da famosa afirmação heideggeriana "já só um deus nos pode ainda salvar”, a análise se concentra sobretudo na questão de qual salvação é ainda possível na época do atual domínio da técnica. Segundo a leitura proposta, o deus mencionado por Heidegger não deve ser confundido com qualquer representação histórico-religiosa de deus, mas circunscreve a dimensão do divino que sempre escapa ao controle e à manipulação do homem, não obstante o envolva na profundidade da sua essência. De acordo com a autora, não é, contudo, o próprio deus quem salva o homem. Uma tal perspectiva 
só iria reiterar a imagem tradicional de um deus todo-poderoso, invocado, como ex machina, para restaurar a ordem no caos produzido pelos homens. Pelo contrário, o que salva é o cultivo da recordação de deus, a saudade de nosso vínculo com algo que transcende o âmbito ôntico e o horizonte do manipulável. Nessa perspectiva, tornase claro o convite de Heidegger, sugerido pela entrevista, a colocar em prática um "outro pensar", depois do fim da filosofia, que seja capaz de despertar o homem para aquela dimensão ulterior que permanece escondida no febril planejamento técnico.

O terceiro capítulo aborda a reflexão heideggeriana sobre a arte e pretende mostrar a sua importância para uma plena compreensão do ser humano. A esse respeito, a autora propõe uma reformulação do conceito de "ser-aí", tradução corrente do termo alemão Dasein, que nos ajuda explicar o papel da arte na realização existencial: o Da-sein é o "aí-do-ser", ou seja, o lugar em que o ser se manifesta e ilumina. A arte constitui uma modalidade exemplar por meio da qual - Dasein realiza esse seu posicionamento essencial, na medida em que, criando a obra, funda um espaço, um "aí", para o descobrir-se do ser. Ao cumprir essa função, a arte tem, de acordo com a autora, uma vantagem sobre o pensamento. Se o pensar só raramente seria capaz de ser mais do que uma preparação da possibilidade do encontro homem-ser, na arte, diversamente, essa reunião se daria de maneira direta e imediata. Partindo dessas coordenadas gerais, o terceiro capítulo segue a evolução da longa reflexão heideggeriana sobre a arte, esclarecendo, em particular, o contexto especulativo - a exploração da verdade e do seu acontecer histórico-epocal - que leva Heidegger a focalizar a arte no começo dos anos 1930. A autora se afasta da tese de Pöggeler, segundo a qual a abordagem heideggeriana da arte seria uma simples fuga romântica depois da desilusão política (cf. Pöggeler, 1972), reivindicando, pelo contrário, a íntima ligação dessa abordagem com o percurso especulativo do filósofo e, sobretudo, a função privilegiada que ela vem a assumir servindo a Heidegger de premissa indispensável para a reflexão posterior sobre a técnica. Adotando uma perspectiva diacrônica, a autora defende que as conferências sobre a origem da obra de arte dos anos 1930 (Heidegger, 2002, pp.5-94) já contêm as linhas essenciais da concepção heideggeriana sobre a arte, a qual não seria depois posta em questão, mas só retocada parcialmente nos anos 1950 e 1960 para ser integrada à reflexão sobre a essência do mundo técnico e sobre a Quadrindade (Geviert). Para oferecer um exemplo e uma demonstração dessa tese, a autora passa a traduzir e analisar um breve texto heideggeriano do ano de 1955 sobre o quadro de Rafael, a Madonna Sixtina. Esse escrito não somente conteria todos os elementos-chave definidos na reflexão dos anos 1930, mas também acrescentaria tanto uma meditação mais consciente sobre o destino da obra de arte na época contemporânea, quanto a referência ao conceito de Quadrindade, implícito na ideia de um encontro entre o celestial e o terreno na imagem artística. 
O quarto capítulo se abre com a afirmação de que a consideração heideggeriana da arte está centrada, desde o começo até o final, na crença básica de que a obra representa o ponto de intersecção entre, por um lado, homem e ser e, por outro, entre humano e divino. Em cada fase da sua história, a arte continuaria a executar essa tarefa, oferecendo-se como manifestação do invisível, como espaço de epifania do sagrado. O que muda é, na visão da autora, a maneira como o homem, em diferentes épocas, experiencia o sagrado: se, no mundo grego, o homem parecia dócil e temeroso frente à poderosa manifestação divina, na época contemporânea ele tem apenas um contato frágil com o sagrado através das experiências da morte e da ausência. A autora estuda como exemplos desses dois extremos do processo histórico da arte, por um lado, a figura imponente do templo grego, referência favorita de Heidegger nos anos 1930; e, por outro, a arte minimalista de Klee, à qual o filósofo se aproxima, sobretudo na década de 1960, vendo, na obra do artista, um testemunho da arte pós-metafísica.

No quinto capítulo, a análise se dirige a duas traduções/interpretações que Heidegger conduz a respeito do primeiro estásimo da Antígona de Sófocles: em 1935, no contexto do curso Introdução à Metafísica e, em 1943, para preparar uma edição privada como presente de aniversário a sua esposa. Esse trabalho de assimilação do texto grego, de intensidade análoga àquele dedicado por Hölderlin à mesma fonte nos anos de 1799 e de 1802-1803, é considerado pela autora como um laboratório fundamental para a gênese da concepção heideggeriana da técnica. No comentário interpretativo do estásimo, desenvolvido no curso Introdução à Metafísica, começa a anunciar-se o interesse de Heidegger pela questão da técnica, a qual se tornará tema central a partir dos anos 1950. Com base no texto de Sófocles, Heidegger elabora uma ontologia da essência do humano como ser duplamente inquietante (unheimlich): num sentido positivo, ele é unheimlich em virtude do seu poder criador e violento que força o ser a manifestar-se no ente; por outro lado, o ser humano se revela terrível também num sentido negativo, podendo perverter a sua energia criativa num exercício de controle e de programação rígida que oprime a livre doação do ser.

O sexto capítulo examina o particular estilo de pensar posto em prática nos Beiträge zur Philosophie de Heidegger. O problema que surgiu na elaboração dessa obra, e que deve ter sido um motivo para a decisão heideggeriana de não a publicar imediatamente, foi o de individuar uma linguagem adequada para captar e manifestar o Ereignis. A autora traduz esse conceito fundamental dos Beiträge como "acontecimento propício", destacando, assim, tanto o aspecto de apropriação recíproca (sublinhado na ressonância da raiz latina prope), quanto a componente cairológica do instante propício em que acontecem simultaneamente o lance do ser (Zuwurf) e o projeto humano (Entwurf). Como o ser é em si indizível, o pensar que lhe pode dar voz é nomeado por Heidegger de "sigética" (com referência 
ao verbo grego sigân, "calar”) e é caracterizado, por um lado, como um acolher cauteloso e reservado, não impositivo; e, por outro, como um dizer não assertivo, mas questionador, aberto e itinerante. Esse estilo de pensamento, que deixa para trás os sistemas da metafísica, é enraizado no afeto fundamental (Grundstimmung) da reserva (Verhaltenheit), entendida como proximidade discreta e receptiva ao acontecimento do ser. 0 reconhecimento desse enraizamento do pensar na dimensão afetiva é bem detectado pela autora e a leva à justa intuição de identificar o medium da inter-relação entre ser e homem na disposição (Stimmung), na "porosidade afectiva" (p.151). Desse acolhimento afetivo do lance do ser surge um pensar que se configura como obra de arte arquitetônica ou musical, na medida em que ele oferece ao ser um espaço internamente construído e articulado (na sequência harmônica das chamadas "fugas") para a sua manifestação.

No sétimo capítulo, expõe-se a concepção heideggeriana da técnica, com base no escrito Die Frage nach der Technik, publicado em 1954. Pensar a técnica representa a tarefa fundamental do "outro pensar", pela qual Heidegger pretende ultrapassar a metafísica. Querendo imprimir à sua reflexão uma marca estritamente ontológica, Heidegger distancia-se tanto de uma abordagem ética, que implicaria uma tomada de posição a favor ou contra a técnica, quanto da concepção vulgar desse fenómeno enquanto instrumento funcional às finalidades humanas. A forma de relacionamento técnico em que o homem moderno está preso, ou seja, o desfrutamento calculador da natureza para fins de autoconservação, pode ser compreendida plenamente somente a partir do reconhecimento da essência da técnica, que consiste no chamado Ge-stell. Segundo a autora, esse termo conceitual não é "infeliz", mas é muito adequado, pois permite explicar três traços fundamentais da técnica. Em primeiro lugar, o prefixo ge- revela que essa palavra define um conjunto de comportamentos sociais e humanos e que, aliás, é o resultado de um processo genético. Em segundo lugar, o verbo stellen evidencia o ato do pôr, que é ambivalente, pois indica tanto o "deixarser" da techne grega, isto é, o libertar a natureza para a sua luminosa manifestação no ente produzido, quanto a tendência a im-por, típica da racionalidade moderna. Finalmente, Ge-stell traz à mente a Gestalt, a figura, sendo que a técnica é a forma, o esquema prévio aplicado à realidade para torná-la correspondente à exigência de uma vontade dominadora e interessada na conservação e no progresso do bemestar humano. A tradução mais apropriada para exprimir essa tripla determinação presente no termo Ge-stell é, de acordo com a autora, a de "com-posição". Partindo dessa precisa análise lexical, a autora descreve a essência da técnica moderna como uma "estrutura estruturante", pois ela é, ao mesmo tempo, tanto a configuração moderna da relação homem-ser e quanto aquilo que determina de antemão cada comportamento humano. Ao expor o raciocínio heideggeriano, a autora sublinha, enfim, a duplicidade, a natureza de Jano, da técnica moderna, a qual não representa 
somente o perigo extremo, enquanto esquecimento do ser, mas contém em si também a chance de salvação. Essa última repousa no vínculo originário homem-ser, que ainda é perceptível, embora fracamente, em nosso mundo técnico. A experiência repentina desse vínculo pode levar o homem a recuperar o sentido primitivo da técnica que estava em vigor no mungo grego, e a exercer um saber criativo, que não é mais um fazer opressivo, mas um pôr-se-em-obra da verdade.

No último capítulo do livro, a autora volta à questão da técnica e esclarece a sua íntima conexão com a da arte. Com a publicação do texto Die Frage nach der Technik, a meditação heideggeriana sobre a arte, iniciada nos anos 1930, chegaria ao seu pleno desdobramento. Nesse texto, seria trazido à luz e explicitado um elemento que, nas conferências dos anos 1930, ainda permanecia implícito: o da união profunda entre arte e técnica em virtude da sua comum proveniência, a techne grega. No seu sentido autêntico, arte e técnica são modos da techne, isto é, do pôr-se-em-obra da verdade do ser. Contudo, esse "pôr", no mundo grego, correspondia, de maneira dócil e cheia de assombro, ao desencobrir-se do ser. Assim, foi apenas a partir da modernidade que se perdeu a capacidade de se surpreender, e que se afirmou a necessidade de certeza e segurança - a qual transformou o saber produtivo originário num ávido projeto calculador. A única salvação que se delineia para a nossa época é aquela que consiste na realização do "passo atrás", isto é, na recuperação do perdido sentido antigo da técnica como saber produtivo, respeitoso da dinâmica de manifestação-retraimento do ser. Nisso resume-se, substancialmente, a mensagem da conferência de Atenas de 1967, intitulada A proveniência da Arte e a determinação do Pensar, cuja abordagem representa a conclusão do livro e o ápice da longa interrogação heideggeriana sobre a essência da arte.

Depois dessa breve exposição das teses principais defendidas no texto, gostaríamos de apontar algumas questões que são aludidas pela autora, sem, contudo, ser objeto de uma tematização detalhada, e que estimulam possíveis caminhos para um aprofundamento futuro.

Para uma plena compreensão da reflexão heideggeriana sobre a arte, parecenos imprescindível levar em conta os Beiträge zur Philosophie, nos quais a arte é definida, ao lado de outros modos, como uma das vias de abrigo (Bergung) da verdade no ente. Dentre esses outros modos, é mencionada a fabricação de utensílios (cf. Heidegger, 2015, §32, p.73)1', isto é, a técnica artesanal. Então, no conceito de Bergung, Heidegger pensa, já nos anos 1930, a essência comum da arte e da técnica, ambas as quais são, no seu sentido autêntico e primordial, produções capazes de incorporar a verdade do ser no ente produzido. Além disso, com os Beiträge, cujo projeto já está fixado no seu núcleo central em 1932, surge o primeiro contexto de investigação sobre a essência da técnica moderna, que aqui é designada como

1 Veja-se também: Heidegger, 2015, § 242, p.378; § 243, p.379. 
maquinação (Machenschaft). A esse respeito, não se pode esquecer que, dentre os sintomas da época da maquinação, é mencionado o generalizado mal-entendido acerca da essência da arte, a qual - observa Heidegger - está sujeita hoje ao consumo cultural e é reduzida a mero estimulador de vivências subjetivas (Erlebnisse) (cf. idem, § 56, p.116; § 44, p.92). Essa referência aos Beiträge permite afirmar que, desde a sua primeira concepção, a reflexão heideggeriana sobre a arte está ligada à meditação sobre a técnica: o que Heidegger argumentará nos anos 1950 e 1960 é apenas um desenvolvimento mais amplo do que está contido de forma substancial nos Beiträge. Já nos anos da elaboração (desde 1932) e, depois, da redação dos Beiträge (1936-1938), Heidegger, portanto, não somente concebia a arte como uma maneira de abrigar a verdade ao lado da produção técnica de utensílios (no sentido da techne grega), como também estava perfeitamente ciente do risco ao qual a arte está submetida na época da maquinação. Mas isso não é tudo. Muitos anos antes da conferência de Atenas, Heidegger formulara de maneira explícita, embora ainda de forma interrogativa, a ideia de "uma outra origem da arte" (idem, § 277, p.489), isto é, a possibilidade de que ela volte a ser novamente um meio para a fundação da verdade. A confirmação dessa possibilidade parece vir das anotações heideggerianas sobre a arte de Klee. De fato, o artista personifica, aos olhos de Heidegger, a figura exemplar do "vindouro" (um dos poucos raros Zukünftige de que Heidegger fala nos Beiträge). Enquanto vindouro, Klee está imerso no afeto fundamental da reserva e na experiência autêntica da morte e, por isso, está receptivo para o dar-se do ser e o acenar do "deus derradeiro" (letzter Gott). Em última análise, vê-se que a própria obra dos Beiträge, e a filigrana conceitual aqui delineada, lançam luz sobre toda a sua produção posterior. É essa obra que representa a "chave hermenêutica" para compreender tanto a filosofia da arte heideggeriana quanto a reflexão sobre a técnica ${ }^{2}$, mas, sobretudo - ao que nos parece - para entender a conexão entre elas.

Com a menção dos conceitos heideggerianos de afeto fundamental e de deus derradeiro, levantam-se duas outras questões que podem integrar, de maneira frutífera, o já rico conjunto de problemáticas abordadas pela autora: 1. para compreender a arte é necessário meditar de maneira essencial sobre a essência da Stimmung, do afeto ou da tonalidade; 2 . a arte é possibilidade de abertura àquela que poderíamos chamar de "transcendência teológica". Nesse contexto, pode-se oferecer só algumas sugestões nas duas direções mencionadas. No que diz respeito ao primeiro ponto, a possibilidade de "uma outra origem da arte" parece-nos depender tanto da experiência real da Grundstimmung pelo artista e pelos espectadores, quanto de uma compreensão filosófica transformada, não-metafísica, da afetividade. Se o sentir é reduzido a mero Erlebnis, isto é, a emoção superficial, autocentrada e pobre de verdade, a arte é destinada a sucumbir (cf. Heidegger, 2002, pp.85-6).

2 Veja-se: Herrmann von, 1997, pp.75-86 e também Herrmann von, 1994. 
De fato, como emerge claramente do curso sobre os hinos de Hölderlin dos anos de 1934-1935 (cf. idem, 2004), a obra pode surgir somente de um afeto fundamental e da experiência de verdade que ele oferece. Isso significa que o saber produtivo autêntico, tanto aquele artístico quanto aquele técnico, está sempre fundado na Grundstimmung, pois a afetividade é o medium do encontro entre homem e ser (como já mencionado justamente, mas só brevemente, pela autora). Voltando ao segundo ponto, a arte possibilita a chamada "transcendência teológica", isto é, a relação do homem com o divino, que transparece na ideia heideggeriana do deus derradeiro. 0 motivo dessa revelação concedida pela arte está implícito no fato de que a obra é o que funda a verdade do ser. Sabe-se, de fato, que já nos Beiträge Heidegger distingue o seu conceito de ser daquele de deus, e que ele considera o acontecimento do ser como o horizonte em que o deus se pode ainda manifestar (cf. idem, 2015, § 123, pp.236-238 e § 126, pp.239-240). Portanto, se a obra funda o ser, ela desenrola, assim, o horizonte em que o homem poderia, talvez, encontrar deus.

0 desenvolvimento das duas questões delineadas precisaria, enfim, de um esclarecimento genuíno da Geworfenheit típica da obra de arte. A sua Geworfenheit não exprime somente o fato de que a obra está situada no âmbito mundano e está exposta ao consumo e à decadência. A Geworfenheit da arte sugere o que Platão, de maneira poética, exprimia na ideia da manía erótico-criativa enquanto dom de deus. Analogamente, a arte é, segundo Heidegger, sempre o fruto de uma dádiva que provém do ser. Além disso, o que se pode extrapolar da reflexão inteira do "segundo" Heidegger é a ideia de que esse lance do ser consiste na kháris, isto é, na dinâmica de uma Stimmung originária, sobre-humana e sobre-linguística, que é amor que possibilita, Mögen que ermöglicht (cf. Heidegger, 2005, p.12) ${ }^{3}$. Seguindo essa linha de leitura, aqui só esboçada, a arte resulta ser, em última análise, a resposta hermenêutica possibilitada pelo acontecimento "pático" ou afetivo daquela doação originária.

\section{Referências:}

Heidegger, M. (2002). “A origem da obra de arte”. In: Caminhos de Floresta. BorgesDuarte, I. (ed.). Lisboa: Fundação Calouste Gulbenkian. . (2004). Hinos de Hölderlin. Tradução de Lumir Nahodil. Lisboa: Instituto Piaget.

São Paulo: Centauro. . (2006). “...poeticamente o homem habita...”. In: Ensaios e conferências.

3 Ver também: Heidegger, 2006, p.180. 
Tradução de Emmanuel Carneiro Leão, Gilvan Fogel e Marcia Sá Cavalcante Schuback. $3^{\text {a }}$ ed. Petrópolis: Vozes.

. (2015). Contribuições à filosofia (Do Acontecimento Apropriador). Tradução de Marco Antonio Casanova. Rio de Janeiro: Via Verita.

Herrmann von, F.-W. (1994).Wege ins Ereignis. Zu Heideggers »Beiträgen zur Philosophie«. Frankfurt a.M.: Klostermann. . (1997). „Die „Beiträge zur Philosophie“ als hermeneutischer Schlüssel zum Spätwerk Heideggers”. In: Happel, M. (Org.) Heidegger neu gelesen. Würzburg: Königshausen und Neumann, pp.75-86.

Pöggeler, O. (1972). Philosophie und Politik bei Heidegger. Friburg/München: Alber.

Recebido em: 02.10.2015 Aceito em: 27.02.2016 